\title{
Parental Concerns of Boys with Hypospadias
}

This article was published in the following Dove Press journal:

Research and Reports in Urology

\author{
Phillip Snodgrass' \\ Warren Snodgrass ${ }^{2}$ \\ Nicol Bush ${ }^{2}$ \\ 'Dartmouth Medical Center, Lebanon, \\ $\mathrm{NH}, \mathrm{USA} ;{ }^{2}$ Hypospadias Specialty Center, \\ The Colony, TX, USA
}

Introduction: Reports indicate many parents are negatively impacted by their child's birth defect, experiencing feelings of anxiety, shame, and blame. These reactions have been documented for several conditions, but not hypospadias. We surveyed parents of boys with hypospadias to determine their concerns.

Materials: The validated Impact of a Child with Congenital Anomalies on Parents (ICCAP) questionnaire was administered to parents recruited through social media.

Results: There were 260 respondents ( $80 \%$ female, average age 35 years): $86 \%$ said they had never heard of hypospadias before their son's diagnosis; $57 \%$ of mothers and $38 \%$ of fathers wondered if they were to blame for the hypospadias. This increased to $78 \%$ among women given progesterone during pregnancy. Sixty-four percent reported they worry "a great deal" about their son's health, despite successful repair, which increased to $88 \%$ when surgery was not successful. Twenty percent responded that the surgeon did not spend enough time with them.

Conclusion: Most parents of newborns with hypospadias have never previously heard of the condition. Many wondered if they are to blame for the birth defect, and most reported that they worry "a great deal" about their son's future health, whether or not repair was successful. One in five said surgeons did not spend enough time to discuss these concerns, and one in four said their explanations were unclear. Awareness of these concerns is important for urologists since they are the primary caregivers for patients with hypospadias.

Keywords: birth defect, hypospadias, parent blame, parent anxiety

\section{Introduction}

Among the first questions new parents ask are if their newborn is a boy or a girl, and is their child healthy. Hearing their infant has a birth defect is distressing. There is often fear of the unknown, as parents may have never heard of the condition. Additionally, they are concerned about treatment and the impact the defect and its management will have on their child's life. ${ }^{1}$ Parents may blame themselves for the problem, assuming they must have done, or failed to do, something that resulted in the birth defect. Some may experience the various stages of grief, mourning the loss of the normal child they expected. ${ }^{2}$

The impact of a birth defect on parents has been explored for a variety of conditions, including congenital heart defects, ${ }^{3}$ Down's syndrome, ${ }^{4}$ cleft lip and palate, ${ }^{5}$ and spina bifida. ${ }^{6}$ Although hypospadias is more common than most of these, there are no reports concerning parent concerns about their son's genital anomaly. We surveyed parents of boys with hypospadias to determine their reactions to this diagnosis.

\section{Materials and Methods}

For this descriptive study, parents of boys with hypospadias were recruited from online social networks and provided a link to a voluntary, anonymous survey with 
Institutional Review Board Approval (IntegReview, Austin, TX) in accordance with the ethical principles of the Declaration of Helsinki. Social media groups were found via the search term Hypospadias. All were closed private groups, meaning that members had to be approved by the administrator(s) according to inclusion criteria, including having a son with hypospadias. The group administrators were contacted about the study and provided the survey link, which was posted at their discretion. Survey participation provided implied consent. Demographic information was acquired, and the validated Impact of a Child with Congenital Anomalies on Parents (ICCAP) questionnaire was administered. ${ }^{7}$ The ICCAP includes Likert scale questions designed to identify parents of a child with a birth defect at risk for stress and threatened quality-of-life. It addresses domains including child acceptance, social support, contact with medical providers, and parental fears/anxiety. Answers were coded as Strongly Agree, Agree, Disagree, Strongly Disagree, and Not Applicable. The number and percentage of caregivers responding Strongly Agree/Agree or Strongly Disagree/ Disagree are reported.

Basic questions were asked about their child's hypospadias, including the type of hypospadias (distal, proximal, or unknown); if surgery had been performed, and, if yes, how many surgeries and how long ago; and if surgery was considered successful according to the caregiver answering the survey - defined as a straight penis with an opening at the tip and a normal appearance. In addition, free text responses were requested for the question "What can doctors do to better help you when your son is diagnosed with hypospadias?"

\section{Results}

There were 260 respondents, of whom $80 \%$ were female (average age 35 years) and 20\% male (average 36 years). Of these, $86 \%$ stated they had never heard of hypospadias before their son was diagnosed. If their son had not had hypospadias, 159 (61\%) planned a circumcision, 83 (32\%) did not want a circumcision, and 18 (7\%) were undecided.

Fifty-seven percent of mothers and $38 \%$ of fathers wondered if they are to blame for the hypospadias. This increased to $78 \%$ among women given progesterone during pregnancy. Overall, 58\% reported feeling sad, 24\% feeling angry, and $49 \%$ expressed "fear about my son's expectations for the future", similar between mothers and fathers. In addition, $64 \%$ "worry a great deal about my son's health", $23 \%$ feel their son is different from other boys, but only two (1\%) "wish my son had never been born".

Hypospadias was reported as distal in $48 \%$, proximal in $41 \%$, and unknown in $11 \%$ by the caregivers. Results stratified by severity are presented in Table 1 . Parents of boys with proximal hypospadias reported more feelings of fear/anxiety than those of boys with distal hypospadias, but had similar responses in the domains of social support and interaction with medical providers.

Of the sons, 14\% had no surgery (including those with hypospadias not recommended for repair, and others recommended to undergo repair whose parents elected not to), $33 \%$ had one operation, $22 \%$ had two operations, and the remainder three or more operations. In those who underwent surgery, the average survey response was 2 years (range $<6$ months to 10 years) after the last operation. Among the 25 who were unsure of the severity of their son's hypospadias, five were awaiting surgery and the others reported an average of 1.8 operations, compared to the 1.4 and 2.7 repairs for those with distal and proximal hypospadias, respectively. Surgical success, defined as a straight penis with a normal appearance, was reportedly achieved in $68 \%$, not achieved in $17 \%$, and caregivers were uncertain in $12 \%$. "Worry a great deal about my son's health" increased to $88 \%$ among the 34 in whom surgical success was not achieved.

Among the 260 caregivers, $17 \%$ were not satisfied about their contact with doctors, and 20\% reported there was not enough time spent with the surgeon to answer questions and address their concerns. This was particularly true in $12 / 34$ (35\%) with unsuccessful surgery compared to $17 / 136(12 \%)$ with a successful outcome. Twenty-three percent reported doctors did not explain things clearly (38\% unsuccessful/ $16 \%$ successful), and 39\% wondered if their child will ever be healthy ( $76 \%$ unsuccessful $/ 26 \%$ successful).

Free text comments were made by 164 (63\%) respondents. The most common was that parents wanted more information regarding etiology, treatment options, including prepucioplasty, and expected results from surgery, including no surgery options. They also wished surgeons spent more time, were more honest about their capabilities and results, and showed greater empathy during consultations. Several requested hypospadias support groups. Free text comments are reported in the Appendix.

\section{Discussion}

Even though hypospadias is one of the most common birth defects, there is little public awareness of the condition. Not 
Table I Caregiver Responses to Demographic Questions and ICCAP Statements for Boys with Distal and Proximal Hypospadias. ICCAP Statements are Listed in the Order They Appear in the Questionnaire

\begin{tabular}{|c|c|c|}
\hline & $\begin{array}{l}\text { Distal Hypospadias } \\
(n=127)\end{array}$ & $\begin{array}{l}\text { Proximal } \\
\text { Hypospadias }(n=108)\end{array}$ \\
\hline \multicolumn{3}{|l|}{ Demographic questions } \\
\hline Average age of child at the time of survey & 3.3 years $(S D=3.0)$ & 5.1 years $(S D=4.6)$ \\
\hline Average number of surgeries related to his hypospadias & $\mathrm{I} .4(\mathrm{SD}=\mathrm{I} .3)$ & $2.7(\mathrm{SD}=1.6)$ \\
\hline \multirow{4}{*}{$\begin{array}{l}\text { Was the final outcome of his surgery successful, defined as a straight penis with a normal } \\
\text { appearance? }\end{array}$} & Yes: $64 \%$ & Yes: $44 \%$ \\
\hline & No: $6 \%$ & No: $20 \%$ \\
\hline & Unknown: II\% & Unknown: $24 \%$ \\
\hline & Not applicable: $19 \%$ & Not applicable: $11 \%$ \\
\hline Before your child was born, had you ever heard of hypospadias? (\% Yes) & $13 \%$ & $18 \%$ \\
\hline If your son had surgery, how long ago was his last repair? & 1.9 years $(S D=1.7)$ & 2.0 years $(S D=2.2)$ \\
\hline $\begin{array}{l}\text { The total time the surgeon spent discussing my son's hypospadias condition with me on the } \\
\text { first visit was approximately: }\end{array}$ & 22 minutes $(S D=15)$ & 26 minutes $(S D=16)$ \\
\hline \multicolumn{3}{|l|}{ ICCAP statements: \% reporting agree/strongly agree } \\
\hline I feel sad. & $49 \%$ & $68 \%$ \\
\hline My son faces a difficult life. & $11 \%$ & $44 \%$ \\
\hline I expect my son will be able to function well. & $97 \%$ & $85 \%$ \\
\hline Hypospadias is a heavy burden on my son. & $21 \%$ & $45 \%$ \\
\hline I wonder whether my child will ever be healthy. & $27 \%$ & $47 \%$ \\
\hline My son is facing a difficult period. & $18 \%$ & $53 \%$ \\
\hline My son is the same as other boys. & $85 \%$ & $67 \%$ \\
\hline I feel angry. & $19 \%$ & $28 \%$ \\
\hline Doctors clearly explain things. & $78 \%$ & $76 \%$ \\
\hline Doctors take enough time to listen to me. & $83 \%$ & $86 \%$ \\
\hline I wonder if I am to blame for my son's hypospadias. & $52 \%$ & $68 \%$ \\
\hline I worry a great deal about my son's health. & $55 \%$ & $74 \%$ \\
\hline My friends support me. & $80 \%$ & $75 \%$ \\
\hline I can share worries with my family. & $87 \%$ & $90 \%$ \\
\hline My son will be able to have a normal life later. & $95 \%$ & $80 \%$ \\
\hline I am satisfied about my contacts with doctors. & $81 \%$ & $84 \%$ \\
\hline I feel guilty. & $44 \%$ & $48 \%$ \\
\hline I wish my son had never been born. & 0 & $3 \%$ \\
\hline $\begin{array}{l}\text { The time the surgeon spent with me was sufficient to answer my questions and discuss my } \\
\text { concerns. }\end{array}$ & $76 \%$ & $81 \%$ \\
\hline
\end{tabular}


surprisingly, $86 \%$ of respondents had not previously heard of this congenital abnormality. This lack of awareness, added to reluctance to discuss a penis defect with others, can create a sense of isolation for parents. Many have told us several years after their son's repair that they did not talk about the condition or surgery with others, such as friends and even relatives, who otherwise give them support, but instead faced the uncertainty of reconstruction alone. While $77 \%$ responded that "my friends support me", most of the remaining $23 \%$ responded "Not Applicable", implying they chose not to discuss this with friends as seen in the free text responses. This is important information that our professional societies might use to create awareness campaigns, and it also underscores the need for support groups as requested by several families.

Parents of children with birth defects often blame themselves, wondering what they did, or failed to do, that caused the anomaly. ${ }^{2}$ In this validated ICCAP survey, over half the mothers and a third of fathers indicated they had this concern. For mothers given progesterone during pregnancy, the fear that they were responsible for their son's hypospadias increased to $78 \%$.

While an occasional parent may directly ask if they somehow caused the condition, more often this worry is concealed behind the question of what causes hypospadias. In addition to factual information the urologist might provide, specialists should realize this underlying concern and acknowledge that the parents might be blaming themselves to provide them the opportunity to discuss their fears. Furthermore, during consultations which often focus on surgical repair, parents may not think there is time to mention their concern, and so urologists could consider incorporating this topic into their routine overview of hypospadias.

All parents think about their child's future, and those whose child has a birth defect naturally worry what impact it will have. Most of the boys of parents responding to this survey had already undergone repair, and it is not surprising that $88 \%$ of parents whose sons had unsuccessful surgery "worry a great deal" about his future. This response likely relates to a previous report that complications are strongly associated with decisional regret in parents of boys with distal hypospadias. ${ }^{8}$

However, we also found that two-thirds of parents whose sons had successful repair still worry a great deal about their son's future health. Social networks warn of scarring, decreased penile sensation, and new complications at puberty, which may contribute to parent anxiety. Awareness that many parents have these concerns even after successful surgery will help urologists anticipate them in their perioperative counseling.
Although most respondents were satisfied by their encounters with surgeons, one in five said that not enough time was allotted during office visits to discuss their concerns, and one in four reported their urologist's explanations were not clear. We have changed our practice and now schedule more time for hypospadias consultations. This enables discussion of more than the anticipated surgery and outcomes given what we have learned of these parent concerns and the impact the condition has on the entire family.

Our survey also found that a third of respondents did not want their boy to be circumcised, and free text comments by several emphasized their desire that prepucioplasty be offered. Because surgical outcomes for distal hypospadias are the same when either circumcision or prepucioplasty are done, ${ }^{9,10}$ urologists should provide the option that parents prefer, or refer to a colleague who will perform foreskin repair. Lorenzo et $\mathrm{al}^{8}$ similarly reported that the desire to avoid circumcision was a significant factor in decisional regret after distal hypospadias repair.

Finally, many free text comments called for greater transparency from surgeons regarding their personal results. We have observed that it is parents of sons with distal hypospadias who most commonly express frustration that they were not adequately prepared for complications. Instead, many say they were given the impression from various caregivers that the defect was "minor" and surgery to correct it was nearly always successful. When complications occurred, they felt misled. These feelings can be reinforced by social media networks which indicate their experience is not unique.

There are several limitations to our study. Because this was an open recruitment survey from caregivers on social media (parental hypospadias support groups), we cannot report the specific survey response rate. It is possible that parents either highly satisfied or highly dissatisfied were more likely to respond, skewing the results. This might also explain the greater proportion of responses from parents whose sons had proximal hypospadias than would be expected on the basis of its prevalence. Another limitation is that since it was completely anonymous, we were unable to control for responses from the same household, for instance if both parents participated in the survey, which could potentially impact results. Nevertheless, mothers and fathers may have different perceptions about their child's birth defect and so this limitation does not invalidate results. Finally, the ICCAP was originally administered to parents when their children were 6 weeks and 6 months of age. While responses were similar at both time points, they did tend to improve slightly over time. Therefore, it is possible that the results we report from our 
survey underestimate the impact of congenital hypospadias that would have been seen had we been able to measure earlier.

Altogether, our observations are similar to ICCAP findings from other birth defects, ${ }^{1}$ demonstrating that the majority of caregivers of children with birth defects have such concerns. Furthermore, the high number of respondents shows these findings are pervasive, even among those with reportedly successful repairs. As mentioned above, these results regarding parent reactions to complications, and circumcision when that was not their preference, agree with the decisional regret reported by Lorenzo et al. ${ }^{8}$

Because of their knowledge of hypospadias, including its causes, management, and outcomes, pediatric urologists are the primary physicians for the condition and parents rely on them for most of their medical information. Results of this survey suggest we expand our discussions beyond an emphasis on surgery to also acknowledge parental feelings of fear and blame regarding this birth defect, and worries for their son's future even when repair is successful.

\section{Conclusions}

Most parents have never heard of hypospadias when told their newborn son has the condition, which presents a challenge to professional societies to increase public awareness. Both mother and father may worry that they were to blame for the birth defect, and urologists can provide reassurance in addition to their scientific explanations regarding hypospadias etiologies. While it could be expected that parents of boys with complications were concerned about their son's future, it has not previously been reported that nearly two-thirds had a similar concern even when surgery was successful. Discussing future prognosis during perioperative consultations could help reduce such anxiety. One in every five parents reported the surgeon did not spend enough time to answer their questions and respond to their concerns, and one in four said that their urologist's explanations were not clear. Knowledge of these criticisms can lead to improved communication between urologists and parents of boys with hypospadias.

\section{Disclosure}

The authors report no conflicts of interest in this work.

\section{References}

1. Fonseca A, Nazare B, Canavarro MC. Parenting an infant with a congenital anomaly: an exploratory study on patterns of adjustment from diagnosis to six months post birth. J Child Health Care. 2014;18:111-112. doi:10.1177/1367493512473856

2. Lemack J, Fowles K, Mateus A, Thomas K. Insights from parents about caring for a child with birth defects. Int J Environ Res Public Health. 2013;10:3465-3482. doi:10.3390/ijerph10083465

3. Woolf-King SE, Anger A, Arnold EA, Weiss SJ, Teitel D. Mental health among parents of children with critical congenital heart defects: a systematic review. J Am Heart Assoc. 2017;116:4862.

4. Skotko BG, Levine SP, Goldstein R. Having a son or daughter with Down syndrome: perspectives from mothers and fathers. Am J Med Genet. 2011;155:2335. doi:10.1002/ajmg.a.34293

5. Zeytinoglu S, Davey MP, Crerand C, Fisher K, Akyil Y. Experiences of couples caring for a child born with cleft lip and/or palate: impact of the timing if diagnosis. J Marital Fam Ther. 2016;43:82. doi:10.1111/jmft.12182

6. Malm-Buatsi E, Aston CE, Ryan J, et al. Mental health and parenting characteristics of caregivers of children with spina bifida. $J$ Pediatr Urol. 2015;11:65. doi:10.1016/j.jpurol.2014.09.009

7. Mazer P, Gischler SJ, Koot HM, Tibboel D, van Dijk M, Duivenvoorden HJ. Impact of child with congenital anomalies on parents (ICCAP) questionnaire; a psychometric analysis. Health Qual Life Outcomes. 2008;6:102. doi:10.1186/1477-7525-6-102

8. Lorenzo AJ, Pippi Salle JL, Zlateska B, Koyle MA, Bagli DJ, Braga LHP. Decisional regret after distal hypospadias repair: single institution prospective analysis of factors associated with subsequent parental remorse or distress. J Urol. 2014;191:1558. doi:10.1016/j. juro.2013.10.036

9. Suoub M, Dave S, El-hout Y, Braga LHP, Farhat WA. Distal hypospadias repair with or without foreskin reconstruction: a single-surgeon experience. J Pediatr Urol. 2008;4:377. doi:10.1016/ j.jpurol.2008.01.215

10. Snodgrass W, Dajusta D, Villanueva C, Bush N. Foreskin reconstruction does not increase urethroplasty or skin complications after distal TIP hypospadias repair. J Pediatr Urol. 2012;9:401. doi:10.1016/j. jpurol.2012.06.008

\section{Publish your work in this journal}

Research and Reports in Urology is an international, peer-reviewed, open access journal publishing original research, reports, editorials, reviews and commentaries on all aspects of adult and pediatric urology in the clinic and laboratory including the following topics: Pathology, pathophysiology of urological disease; Investigation and treatment of urological disease; Pharmacology of drugs used for the treatment of urological disease. The manuscript management system is completely online and includes a very quick and fair peer-review system, which is all easy to use. Visit http://www.dovepress.com/ testimonials.php to read real quotes from published authors. 